\title{
Micipsa - MKWSN : Note linguistique complémentaire
}

\section{S. Chaker}

\section{(2) OpenEdition}

1 Journals

\section{Édition électronique}

URL : https://journals.openedition.org/encyclopedieberbere/593

DOI : 10.4000/encyclopedieberbere.593

ISSN : 2262-7197

\section{Éditeur}

Peeters Publishers

\section{Édition imprimée}

Date de publication : 31 décembre 2010

Pagination : 4989-4990

ISBN : 978-90-429-2369-0

ISSN : 1015-7344

\section{Référence électronique}

S. Chaker, « Micipsa - MKWSN : Note linguistique complémentaire », Encyclopédie berbère [En ligne], 32 | 2010, document M107b, mis en ligne le 06 novembre 2020, consulté le 07 décembre 2022. URL http://journals.openedition.org/encyclopedieberbere/593; DOI : https://doi.org/10.4000/ encyclopedieberbere.593

Ce document a été généré automatiquement le 17 février 2022.

Tous droits réservés 


\section{Micipsa - MKWSN : Note linguistique complémentaire}

\section{S. Chaker}

1 Les inscriptions libyques (et puniques) ne fournissent que les consonnes. La forme gréco-latine, apparemment assez éloignée de l'original libyque, présente néanmoins une correspondance quasi «normale » avec celui-ci : les finales $-\mathrm{N}$ du libyque sont régulièrement rendues par un -a latin (cf. Masinisa/MSNSN) et il existe plusieurs exemples de correspondances libyque-W-/latin-grec/p/en position médiane/implosive (Capusa / KWSN).

2 En berbère actuel, la tendance à traiter, dans certains contextes, /w/ en [b, p] est bien attestée, notamment dans les parlers de la Grande Kabylie (cf. /tawwurt/, "porte » > [tabburt, tappurt]). Il n'est donc pas impossible que la forme gréco-latine Micipsa repose sur une variante régionale libyque caractérisée par cette réalisation $/ w />[b$, p]; de nombreux indices autorisent à penser qu'un tel traitement phonétique était attesté en Numidie : cf. latin Thugga / libyque TBGG, couple qui permet de postuler une forme «standard »/TWGGa/, avec traitements locaux [tūgga, $\theta$ ūgga], à l'origine de la forme gréco-latine, et une variante TBGGa, qui correspondrait à la forme de l'inscription libyque RIL 2.

3 En onomastique* libyco-berbère, la séquence MKWSN peut renvoyer à un schème nominal fréquent, dans lequel le - $\mathrm{N}$ final serait une marque de pluriel, et le $\mathrm{M}$-initial un préfixe dérivationnel de nom d'agent (M-KWS-N), ce qui ferait reposer cet anthroponyme sur une racine ${ }^{*}$ KWS ; mais d'autres analyses sont possibles, le M-initial pouvant être une marque dérivationnelle verbale (médio-passif) et le - $\mathrm{N}$ étant une marque très polyvalente: indice verbal de $3^{\mathrm{e}}$ personne de masculin pluriel («ils»), marque de participe verbal, notamment.

4 Par ailleurs, d'autres analyses, impliquant des découpages morphématiques différents, sont également possibles :

$5 \mathrm{M}-\mathrm{KW}+\mathrm{SN}$ : syntagme nominal dans lequel le segment $\mathrm{M}-\mathrm{KW}$ serait un nom dérivé par préfixe $\mathrm{M}$ - (nom d'agent ou autre nom verbal) sur une racine * $\mathrm{KW}$, et le morphème -SN 
un suffixe personnel (possessif) de $3^{\mathrm{e}}$ personne de masculin pluriel (leur); l'anthroponyme s'interprétant alors comme : « Leur X ».

6 MKW-SN : syntagme verbal à suffixe personnel (pronom régime indirect) de $3^{e}$ personne de masculin pluriel (à eux) ; l'anthroponyme s'interprétant alors comme «il X-à eux ».

7 Ces deux dernière hypothèses paraissent devoir être privilégiées dans la mesure où elles sont confortées par l'existence de nombreux parallèles, antiques, médiévaux et contemporains, composés d'un noyau nominal ou verbal suivi d'un affixe personnel de $3^{\mathrm{e}}$ personne de masculin pluriel (leur/à eux/les), le plus fameux étant MSNSN (MS(-)NSN), Massinissa*, mais on peut en citer de nombreux autres : YRN-TN/TRN-TN, YL-SN, Jugurtha* (YuGuR-TN, Yaghmurasen* (Yaghmur-asen), Gellid-asen, YRTN/Yiraten (Yira-ten)...

\section{BIBLIOGRAPHIE}

Sur les questions d'onomastique berbère ancienne, on trouvera un cadre général d'analyse dans : CHAKER S., "Onomastique berbère ancienne (Antiquité/Moyen âge) : rupture et continuité », BCTH, n.s., 19, 1983 [1985], p. 483-497 ; repris dans Textes en linguistique berbère, Paris, Editions du CNRS, 1984, et Alger, Bouchène, 1991, chap. 14).

CAMPS G., « Liste onomastique libyque d'après les sources latines », REPPAL, VII-VIII, 1993, p. 39-73.

INDEX

Mots-clés : Diachronie, Etymologie 